\title{
PSICOLOGIA ECONÔMICA
}

\author{
Vera Rita de Mello Ferreira \\ PUC-SP
}

O campo da Psicologia Econômica, que começa a nascer no Brasil, é apresentado nesta pensata por meio de um breve panorama histórico da produção de conhecimento na intersecção Psicologia-Economia, seus principais campos de atuação e objetos de estudo, bem como o estágio de seu desenvolvimento no Brasil.

A produção brasileira, que começou a ganhar corpo nosúltimos anos, é local izada em al guns de seus exemplos mais significativos. Adicionalmente, são levantados al guns temas para uma agenda brasileira de pesquisa na área, apontando para as possibilidades de participação no debate mais amplo das questões socioeconômicas enfrentadas no Brasil. Essa discussão enfatiza a importância do diálogo interdisciplinar e da necessidade de novos estudos dentro dessa perspectiva.

\section{A emergência da área}

Embora a expressão "Psicologia Econômica' pareça ter sido usada pela primeira vez em 1881, por Gabriel Tarde, pensador social e jurista francês, num artigo para um periódico de filosofia (Barracho, 2001, Van Raaij, 1999), essa disciplina veio a se conso- lidar, efetivamente e em diversas esferas, a partir da década de 1970.

Em sua "pré-história", pode-se identificar, entre os economistas, preocupações que vão além do escopo tradicional da Economia, na chamada Escola Psicológica Austríaca, liderada por Karl M enger, que na segunda metade do século XIX buscava motivações psicológicas que fundamentassem o comportamento dos agentes econômicos (Reynaud, 1967, Wärneryd, 2005), e mesmo no próprio Adam Smith, em seu A teoria dos sentimentos morais, de 1759 (Kirchler, 2003, W ärneryd, 2005).

Contudo, essa área de conhecimento, localizada na fronteira entre Psicologia e Economia, que estuda 0 comportamento econômico dos indivíduos e grupos a partir de diferentes vértices teóricos e metodológicos, observa um crescimento consistente na segunda metade do século XX, com os trabal hos de Pierre-Louis Reynaud (1967), na Europa, e George Katona (1975), na América do N orte.

Desde então, a disciplina passou a integrar a grade curricular de universidades européias e norte-americanas, com programas de pesquisa, congressos anuais, escolas de verão, workshops e o periódico Journal of Economic Psychology. É encontrada também na Nova Zelândia, Austrália e em alguns países da América Latina, como Chile, Colômbia, Argentina e Venezuela.

Dois prêmios Nobel foram outorgados a estudiosos dessa interface: em 1978, a Herbert Simon, por sua teoria da racionalidade limitada (1978), e mais recentemente, em 2002, a Daniel Kahneman, que havia desenvolvido, juntamente com Amos Tversky, já falecido, a teoria do prospecto (Kahneman e Tversky, 1979; Kahneman, 2002), tendo ambas as linhas de pesquisa contemplado análises sobre o processo decisório.

\section{Disciplinas fronteiriças}

Além da Psicologia Econômica, constituída principalmente por psicólogos, economistas experimentais e administradores de empresas, com a participação também de especialistas em consumo, marketing, teoria da informação e tributação, entre outros, encontramos hoje as seguintes disciplinas debruçando-se sobre temas bastante próximos:

Economia Comportamental, ${ }^{1}$ considerada "área irmã" da Psicologia 
Econômica, reúne porém, em sua maioria, economistas interessados em ampliar seu campo de estudo com a ajuda de disciplinas como Psicologia, Sociologia, Antropologia, História e Biologia (http://www.usask.ca/economics/SABE, 2002);

Finanças Comportamentais, uma ramificação da Economia Comportamental, que vem evoluindo a partir da década de 1990 e estuda o comportamento do mercado com base tanto em teorias da Economia tradicional como em acréscimos trazidos pela Economia Comportamental e pela Psicologia Econômica ( Milanez, 2001; Macedo, 2004);

Socioeconomia, com sociólogos e cientistas políticos estudando fenômenos econômicos a partir de formulações sociológicas e políticas (http:// www.sase.org/aboutsase/aboutsase. html \#W SE, 2004);

Psicologia do Consumidor, área mais conhecida, quetrata das questões referentes ao consumo de um ponto de vista psicológico (http://www.consuma.cjb.net, 2005);

Neuroeconomia, a mais nova área, que busca alicerces neurológicos para explicar as decisões econômicas, com os estudos de neurocientistas, economistas e psicólogos (http://www.richard.peterson.net/N euroeconomics. htm, 2005).

Essa breve exposição das disciplinas permite-nos verificar que o campo de conhecimento mais amplo que as reúne aponta para tendências da ciência de um modo geral - da possibilidade de integração, buscada desde 0 final do século XIX até o início do século XX, quando a própria Psicologia ainda lutava por se fazer reconhecida, eeconomistas recorriam a seus conhecimentos sobre a mente, dentro do âmbito do senso comum, para embasar suas propostas, até a atualidade, quando a neurociência ganha grande impulso e visibilidade, com a ajuda dos avanços tecnológicos de nossa era, passando pela disputa interna das linhas comportamental e cognitiva dentro da Psicologia, quevem a refletir-se, igualmente, na Psicologia Econômica e demais áreas de convergência.

\section{Linhas de pesquisa}

No Brasil, assistimos a um crescimento expressivo da produção na interface Psicologia-Economia no início deste século XXI, particularmente no que diz respeito ao campo das Finanças Comportamentais. ${ }^{2} \mathrm{~N}$ aturalmente, 0 intercâmbio entre todas as disciplinas citadas énão apenas possível como desejável, uma vez que o conhecimento compartilhado sobre o comportamento econômico de indivíduos e grupos enriquece cada uma del as. Ao mesmo tempo, vemos crescer também o interesse pela Psicologia Econômica.

Dentro dela encontramos, atualmente, diversas linhas de pesquisa, dentre as quais podemos destacar: psicologia do dinheiro, da poupança, do investimento, da dívida; tomada de decisão; economia experimental; comportamento do consumidor; comportamento econômico de crianças; psicologia do trabal ho; meio ambiente; administração financeira; evasão fiscal; psicologia do turismo; psicologia da pobreza; desemprego; políticas econômicas.

As bases teóricas mais utilizadas são a Psicologia Comportamental e a Psicologia Cognitiva, embora outras possam ser encontradas, ainda que mais raramente, como a Psicanálise e a Psicologia Evolucionária. Do ponto de vista metodológico, há grande preferência por dados empíricos reunidos a partir de experimentos em laboratório ou grandes levantamentos junto à população.

As informações obtidas por meio desses estudos visam complementar 0 conhecimento sobre as questões econômicas conforme ocorram na realida- de, em oposição ao uso de axiomas e fórmulas matemáticas, tal como costuma ser feito na Economia tradicional. Nesse sentido, a grande discrepância entre as duas abordagens dá-se em torno da teoria da racionalidade, que postula a tendência geral, inerente ao ser humano, a tomar sempre as melhores decisões econômicas, maximizando seus ganhos, dadas as condições de obter-se informações de maneira ótima (Lea, Tarpy e Webley, 1987).

A Psicologia Econômica questiona essas suposições com base em dados coletados em simulações experimentais de situações da realidade e por intermédio de levantamentos e questionários, ou ainda por meio da própria observação direta dos fenômenos, cotejadas com concepções sobre operações psíquicas básicas.

\section{PERSPECTIVA BRASILEIRA}

No Brasil, depois de iniciativas isoladas entre as décadas de 1930 e 1950, sob a forma de disciplinas situadas na intersecção PsicologiaEconomia (Bomfim, 2004; M ancebo, 1999; Penna, 1992), começamos a ter investigações dentro desse campo mais notadamente a partir da década de 1990.

No início dos anos 2000, uma linha de pesquisa em Psicologia Econômica é introduzida no programa de Mestrado em Psicologia, da Universidade Federal do Pará, em Belém, sob coordenação da professora Alice M oreira, gerando dissertações (Lauer-Leite, 2003; Albuquerque, 2003) e pesquisas.

Em 2006, identificamos um volume crescente de produção: há economistas, administradores de empresas e psicólogos real izando trabal hos nessa interface, iniciada na década passada, mas ganhando impulso na atualidade (Ferreira, 2006). Os temas abordados 
vão da inflação (Vieira et al., 1993; Ferreira, 2000) ao significado do dinheiro (M oreira, 2000), passando, em seu escopo mais amplo, por finanças comportamentais, psicologia do consumidor e educação financeira, entre outros.

Os vértices de pesquisa e métodos adotados apresentam variações, podendo haver, por exemplo, desde estudos transdisciplinares (Vieira et al., 1993) até criação de escalas próprias (Moreira, 2000), bem como pesquisas sobre tomada de decisão em situações clássicas da Economia, numa produção que cresce de modo intenso nos últimos anos (cf. Cunha, 2005; Mantovanini et al., 2003; Kimura et al., 2004; Nunes, 2004).

Acreditamos, assim, ser importante refletir sobre a Psicologia Econômica que desejamos desenvolver em nosso país. Como proposta inicial, fazemos a sugestão de nos voltarmos para as questões apresentadas por nossa realidade e, ao mesmo tempo em que mantemos contato com os centros de estudo da área já estabelecidos, intensificamos também o intercâmbio científico com países em desenvolvimento, na América Latina e em outros continentes.

Os temas de pesquisa podem guardar especificidades, em nosso país, que mereçam investigação minuciosa erigor no método escolhido para estudá-los. A ampliação em direção a outras abordagens que possam oferecer subsídios para uma investigação mais completa das operações psíquicas, como aquela trazida pela Psicanálise, por exemplo, também imprimiria um caráter próprio à disciplina no país.

Outro ponto nessa agenda diz respeito à importância de se pensar sobre a possibilidade de um trabal ho de informação econômica voltado para a população em geral, abrangendo tanto aspectos do funcionamento da Economia como do comportamento humano frente a esses fenômenos, e integrando diferentes profissionais, como psicólogos, economistas, psicanalistas, administradores, publicitários, analistas do discurso e outros.

Para concluir, acrescentamos também a possibilidade de se fazerem contribuições a políticas econômicas a partir do conhecimento psicológico em torno de decisões econômicas, cuja viabilidade tem sido demonstrada em algumas experiências realizadas na Austrália e Nova Zelândia (Earl, 2005). Tomando-se o ponto de vista de psicólogos econômicos (Lewis, Webley e Furnham, 1995) e economistas psicológicos (Earl, 1990) a respeito das limitações impostas por uma visão "puramenteeconômica" da Economia, identificamos a necessidade de uma abertura desse campo para 0 enriquecimento trazido por teorias psicológicas.

No caso do Brasil, nossas necessidades de reflexão cuidadosa acerca dos rumos de nossa Economia parecem impor ainda maior urgência à interdisciplinaridade. U ma Psicologia Econômica brasileira, portanto, deveria contribuir para o avanço do nosso país em direção a mel hores condições de vida e trabalho, com vistas a uma gestão mais transparente das decisões sobre questões socioeconômicas e psicológicas, tanto no âmbito público como no individual.

\section{NOTAS}

1. Sobre essa disciplina, cabe observar que alguns pesquisadores dão preferência ao termo alternativo "Economia Psicológica" (Katona, 1975; Earl, 1990), possivelmente com o objetivo de estender o sentido do termo "psicológico" para além do comportamento em si.

2. Como ilustração dessa expansão, foram encontrados, em duas datas de 2006, os seguintes resultados para buscas, na Plataforma Lattes, para as palavras-chave que se seguem: em 17.01.06,
20 pesquisadores para Psicologia Econômica, 10 para Economia Comportamental, nenhum para Economia Psicológica, 37 para Finanças Comportamentais, nenhum para N euroeconomia; em 07.05.06, 20 para Psicologia Econômica e nenhum para Economia Psicológica, mas agora, 15 para Economia Comportamental e 42 para Finanças Comportamentais, e um surge para $N$ euroeconomia, na verdade referente ao curso de Ferreira na Cogeae da PUC-SP.

\section{REFERÊNCIAS}

ALBUQUERQUE, G. T. A relação entre o significado do dinheiro e o significado do salário para motoristas e cobradores de transporte coletivo urbano. Dissertação de Mestrado em Psicologia, Universidade Federal do Pará (UFPA), Belém, 2003.

APRESENTAÇÃO DO GRUPO DE PESQUISA SOBRE PSICOLOGIA DO CONSUMIDOR da Universidade de Brasília. Disponível em: বttp://www.consuma.cjb.net>. Acesso em: 30 abr. 2005.

APRESENTAÇÃO SOBRE NEUROECONOMIA. Disponível em: বhttp://www.richard.peterson. net/N euroeconomics.htm $>$. Acesso em: $26 \mathrm{dez}$. 2005.

APRESENTAÇÃO SOBRE SÓCIO-ECONOMIA E A SUA ASSOCIAÇÃO, SASE. Disponível em: «ttp://www.sase.org/aboutsase/aboutsase. html\#W SE>. Acesso em: 18 jul. 2004.

APRESENTAÇÃO SOBRE ECONOMIA COMPORTAMENTAL E SUA ASSOCIAÇÃO, SABE. Disponível em: «ttp://www.usask.ca/economics/SABE>. Acesso em: 01 ago. 2002.

BARRACHO, C. Lições de psicologia econômica. Lisboa: Instituto Piaget, 2001.

BOMFIM, E. M. Históricos cursos de psicologia social no Brasil. Psicologia Social, v. 16, n. 2, p. 32-36, 2004.

CUNHA, F. B. C. Incerteza, racionalidade e escoIha: os novos rumos da teoria econômica. Tese de Doutorado. Instituto de Economia da UFRJ, Rio de Janeiro, 2005.

EARL, P. Behavioral economics and the economics of regulation. Briefing paper prepared for the New Zealand Ministry of Economic Development, 2005 (original cedido pelo autor em versão eletrônica). 
EARL, P. Economics and psychology: a survey. The Economic Journal, v. 100, n. 402, p. 718755,1990

FERREIRA, V. R. M. O componente emocional - funcionamento mental e ilusão à luz das transformações econômicas no Brasil desde 1985. Rio de Janeiro: Papel e Virtual, 2000.

FERREIRA, V. R. M. Is economic psychology being born in Brazil? - a review of the scientific production in the interface psychology-economy. In: CONGRESSO DE PSICOLOGIA ECONÔMICA IAREP-SABE JOINT MEETING, 31., Paris. Anais. Paris, 2006.

KAHNEMAN, D. Maps of bounded rationality: a perspective on intuitive judgment and choice. Prize Lecture - Nobel Prize, Dec. 8 ${ }^{\text {th }}, 2002$. Disponível em: <http://nobelprize.org/economics/laureates/2002/kahnemann-lecture.pdf>. Acesso em 24 jan. 2003.

KIMURA, H.; BASSO, L. F. C.; KRAUTER, E. Criação de valor através da estratégia de procrastinação. In: ENCONTRO NACIONAL DE ECONOMIA. Anais. Anpec, 2004.

KIRCHLER, E.; HÖLZL, E. Economic psychology. International Review of Industrial and Organizational Psychology, v. 18, p. 29-81, 2003.

LAUER-LEITE, I. D. Socialização econômica: a aquisição de conceitos econômicos e os comportamentos econômicos de crianças e adolescentes brasileiros. Dissertação de Mestrado defendida no curso de Psicologia da Universidade Federal do Pará, UFPA, 2003.

LEA, S.; TARPY, E. G.; ROGER M.; WEBLEY, P. The Individual in the Economy. Cambridge, UK: Cambridge University Press, 1987.

LEWIS, A.; WEBLEY, P.; FURNHAM, A. The New Economic Mind - The Social Psychology of Economic Behaviour. London: Harvester/ Wheatsheaf, 1995.

MACEDO JR., J. S. Teoria do prospecto: uma investigação utilizando simulação de investimentos. Tese de Doutorado defendida na Universidade Federal de Santa Catarina. Florianópolis, 2003.

MANCEBO, D. Formação em psicologia: gênese e primeiros desenvolvimentos. In: JACÓVILELA, A. M..; RODRIGUES, H. B. C. (Orgs.). Clio-Psyché: histórias da psicologia no Brasil, v. 1, p. 93-120, 1999.

MANTOVANINI, R. E. M. et al. A relação riscoretorno: avaliação de um modelo comportamental no mercado acionário brasileiro. Encontro Anual da Anpad, 2003.

MILANEZ, D. Y. Finanças comportamentais: uma nova abordagem à teoria de finanças. Informativo Fipe. p. 30-34, dez. 2001.

MOREIRA, A. S. Um estudo transcultural da relação entre valores e o significado do dinheiro para indivíduos. Brasília. Tese de Doutorado defendida no programa de Psicologia da Universidade de Brasília. 2000.
NUNES, B. F. Mapas de escolha individual em condições de incerteza. Trabalho de Conclusão de Curso (graduação em Economia), Universidade Federal do Rio Grande do Sul (UFRGS), 2004.

PENNA, A. G. História da psicologia no Rio de Janeiro. Rio de Janeiro: Imago, 1992.

SIMON, H. A. Rational decision-making in business organizations. Nobel Memorial Lecture - Dec. $8^{\text {th }}, 1978$. Carnegie-Mellon University, Pittsburgh, PA: Economic Science, 1978. p. 343-371.

REYNAUD, P. L. A psicologia econômica. São Paulo: Difusão Européia do Livro, 1967.

VAN RAAIJ, W. F. History of economic psychology. In: EARL, P.; KEMP, S. (Eds.). The Elgar Companion to Consumer Research and Economic Psychology. Aldershot, UK: Edward Elgar, 1999.

VIEIRA, J. R.; BARBOSA, L. N. H.; PRADO, L. C. D., LEOPOLDI, M. A. P.; D'ARAUJO, M. C. (Orgs.). $\mathrm{Na}$ corda bamba - doze estudos sobre a inflação. Rio de Janeiro: Relume-Dumará, 1993.

WÄRNERYD, K. E. Consumer image over the centuries. Glimpses from the history of economic psychology. In: GRUNERT, K.; THÖGERSEN, J. (Eds.). Consumers, Policy, and the Environment - A Tribute to FolkeÖlander. N ew York: Springer Verlag, 2005.

\title{
Pensata recebida em 13.07.2006. Aprovada em 06.06.2007.
}

\author{
Vera Rita de Mello Ferreira \\ Professora de Psicanálise e Psicologia Econômica no COGEAE/PUC-SP. Doutora em Psi- \\ cologia Social pela PUC-SP. Representante no Brasil da Iarep-International Association for \\ Research in Economic Psychology. \\ Interesses de pesquisa nas áreas de tomada de decisão; fundamentação psicanalítica para o \\ modelo de tomada de decisão; programas de esclarecimento da população sobre operações \\ econômicas e financeiras, comportamento econômico e funcionamento psíquico. \\ E-mail: verarita@verarita.psc.br \\ Endereço: Rua Itapicuru, 613, cj. 102, Perdizes, São Paulo - SP, 05006-000
}

